\title{
An Experimental Study on the Behavior of Shear Keys According to the Curing Time of UHPC
}

\author{
Hee Seok Kim, Won Jong Chin, Jeong Rae Cho, Young Jin Kim, Hyejin Yoon \\ Structural Engineering Research Institute, Korea Institute of Civil Engineering and Building Technology, \\ Goyang-Si, Republic of Korea \\ Email: lagoon@kict.re.kr, wichin@kict.re.kr, chojr@kict.re.kr, yikim@kict.re.kr, hiyoon@kict.re.kr
}

Received 1 April 2015; accepted 16 April 2015; published 20 April 2015

Copyright (C) 2015 by authors and Scientific Research Publishing Inc.

This work is licensed under the Creative Commons Attribution International License (CC BY). http://creativecommons.org/licenses/by/4.0/

c) (i) Open Access

\begin{abstract}
Precast segmental construction has been recently developed to reduce the construction cost and shorten the construction term as compared to the cast-in-place method in a will to establish the design and erection system of structures using Ultra High Performance Concrete (UHPC). However, this method requires the presence of segmental joints to transfer the loads between neighboring segments, which stresses the importance of securing structural safety and serviceability. Therefore, need is for research on the behavior of the segmental joint for the structures erected by the precast segmental construction method. To that goal, this paper presents an experimental study on the behavior of shear keys with respect to the curing time of UHPC in the segmental joint. Analysis is done on the load-displacement relation according to the curing time of the shear keys and on the failure modes of the shear keys according to the cracking pattern at failure.
\end{abstract}

\section{Keywords}

Ultra High Performance Concrete, Precast Segmental Joint, Curing Time, Shear Key

\section{Introduction}

The recent demand for record-breaking length, height and size of structures has stressed the necessity to develop materials overcoming the limitations of the current high strength concretes and resulted in the development of Ultra High Performance Concrete (UHPC) satisfying basic mechanical characteristics. Research is being conducted on the structural safety and constructability of UHPC for its application in long span bridges like cablestayed bridges and large wind turbine towers. Precast assembly is considered rather than the conventional cast- 
in-place method for the design and construction of structures using this material owing to the reduction of construction cost and shortening of construction period. The erection technique by the precast method was mainly applied for the erection of bridges and was invented in Europe in 1950s by extending the application of the cast-in-place prestressed segmental method. Its first application in Korea dates back to early 1990 and it is now widely applied in numerous bridge construction sites. Besides, even if in-depth research has already been conducted on the structural behavioral characteristics and design specifications of UHPC, there are still very few examples of its application on site in Korea.

The erection of a structure by precast assembly requires unavoidably the presence of joints between the segments. The behavioral characteristics of these joints have critical influence on the structural performance and constructability of the whole structure [1]-[3]. Generally, the joints of the precast structure improve the sectional resistance of each individual member by transferring the load to neighboring members and are intended to secure the safety of the whole structure. The failure of such joint is very likely to result in the collapse of the whole structure, which means that the structural performance of the joint is primordial for the precast structure [4]. Accordingly, the treatment of the segmental joint constitutes the most essential part of the precast structure and necessitates scrupulous study with regard to its behavior.

In general, shear keys are disposed in the segmental joint to transmit effectively the shear stresses and vertical compressive stresses. In such case, the mechanical behavior and the load bearing capacity of the shear keys are critical factors for the shear behavior of the joint. In addition, since the extent of the strength developed according to the curing time of such shear keys has direct influence on the erection speed of the precast structure, it is necessary to determine the appropriate assembly time of the segment with respect to the degree of curing of the shear keys.

This paper presents the experimental study on the behavior of shear keys according to the curing time of curing in the segmental joint necessary for the construction of precast structures. To that goal, test is performed to investigate the behavior of the shear keys with respect to the curing time of UHPC, and the load-displacement relation according to the curing time of the shear keys and the failure modes of the shear keys according to the cracking pattern at failure are analyzed.

\section{Structural Performance Test of Shear Keys}

\subsection{Test Variables and Details of Test}

The shape of the joint, the eventual presence, shape, number and surface state of the shear keys, the transverse restraint stress, the thickness of epoxy and the type of loading are known to influence the behavior of the joint [5] [6]. As reported in the shear tests of joints performed worldwide to date, the shear strength of the shear key joint increases with larger restraint stresses and, the joint develops significantly higher strength when epoxy is applied than when not applied. Moreover, Koseki et al. [7] found out that the epoxy-coated joint shows similar behavior to that of the shear key placed monolithically. However, these results were derived for joints using normal and high strength concretes and not UHPC for which there is still a lack of theoretical and experimental studies [8]. Especially, the absence of study related to the behavior of the shear key according to the curing time of UHPC is noteworthy.

Trapezoidal shear keys in the joints are generally placed monolithically with the segments. The shape of the shear key varies with respect to the inclination angle of the shear key and its protruding height. Yang and Kim [9] studied the characteristics of the structural behavior of joints presenting a ratio $(\mathrm{d} / \mathrm{h})$ of the protruding height (d) of the shear key to its bottom length (h) smaller than 0.3. Referring to the experimental results of Lee et al. [8], this study set this ratio (d/h) to 0.25 giving a bottom length of $100 \mathrm{~mm}$ and protruding height of $25 \mathrm{~mm}$ for the shear key. The authors also set the inclination to $45^{\circ}$ and performed tests on joints equipped with two shear keys.

During the assembly of the segments, compressive stresses act on the concrete section due to prestress and play the role of restraint stresses for the joined section. In addition, the increase of the restraint stresses results in higher shear strength in the joint. In order to derive conservative results, this study restraints only the vertical displacement in the assembled section without introducing restraint stress so as to conduct test on joints without transverse displacement.

Figure 1 displays the detailed dimensions of the specimens adopted in this study. The specimens have a total height of $500 \mathrm{~mm}$, a width of $500 \mathrm{~mm}$ and a thickness of $200 \mathrm{~mm}$. Three segments were precast and assembled by means of two cast-in-place joints. Tests were then conducted to observe the shear behavior of the specimens 

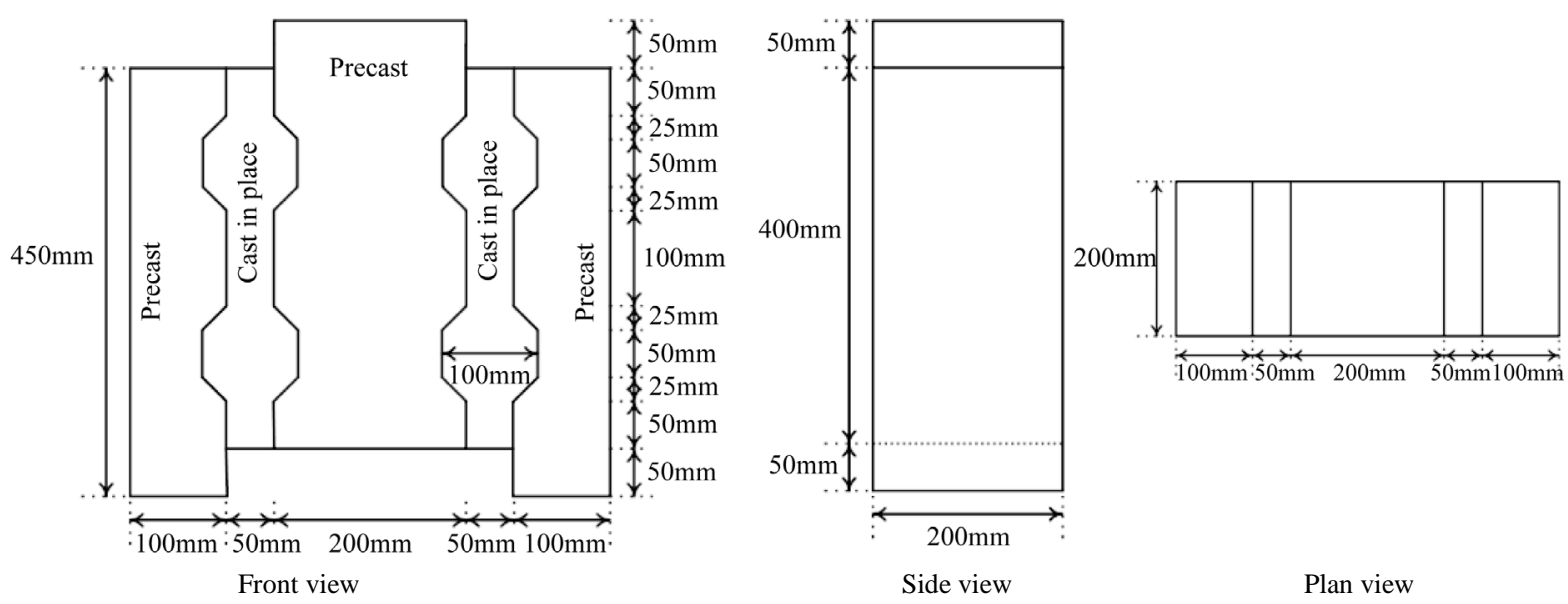

Figure 1. Details of cast in-situ joint specimens.

at curing time of 3, 7, 14 and 28 days of the cast-in-place joints.

\subsection{Mix Composition and Curing of Specimens}

The mix proportions of UHPC adopted in this study are arranged in Table 1. Ordinary Portland cement is used and silica fume is utilized as reactive powder. Their physical and chemical properties are listed in Table 2.

Besides, sand with density of $2.62 \mathrm{~g} / \mathrm{cm}^{3}$ and mean grain size of $0.5 \mathrm{~mm}$ is used as fine aggregate and the use of coarse aggregate was discarded. Polycarbonate superplasticizer (density $1.01 \mathrm{~g} / \mathrm{cm}^{3}$, dark brown) is adopted as high range water reducing agent. Materials with mean particle size smaller than $30 \mu \mathrm{m}$ were used for the filler and were classified into 5 types with respect to the size. Table 3 arranges their chemical properties. KS-13-65-B type steel fiber is adopted and introduced with a volume fraction to concrete of $2 \%$.

Figure 2 presents the fabrication process of the specimen shown in Figure 1. The first placing of UHPC in the forms is executed followed by 3 days of curing at $90^{\circ} \mathrm{C}$ to fabricate the precast segments. These segments are then used as forms for the monolithic placing of the same UHPC to fabricate the cast-in-place shear keys.

A total of twelve specimens were manufactured to verify the behavioral characteristics of the segmental joints according to the strength development of the shear keys. The shear tests were conducted on 3 specimens for each curing time of 3, 7, 14 and 28 days of the cast-in-place shear keys. The curing of the integral shear keys was performed at ambient temperature (mean temperature of $24^{\circ} \mathrm{C}$ ).

\subsection{Test Method}

This study intends to observe only the shear resistance of the cast-in-place integral shear keys in the joints using UHPC. To that goal, the transverse displacement was restrained using an $80 \mathrm{~mm}$-thick steel jig and vertical loading was applied so as to make the interface of the shear key subject to pure shear (Figure 3). The vertical load was applied using a 300 ton-vertical actuator through displacement control at speed of $0.4 \mathrm{~mm} / \mathrm{min}$.

Five displacement sensors (LVDT) were disposed on the front of the specimen to measure the vertical displacement of the shear keys with respect to the load. In order to examine the concrete strain at the surface of the joint, 9 concrete gages were bonded at inclination of $0^{\circ}, 45^{\circ}$, and $90^{\circ}$ on the rear face of the specimen.

\section{Test Results and Discussion}

\subsection{Analysis of Crack and Failure Behavior}

The causes for the failure of the shear key can be distinguished as follows: a) occurrence of inclined cracking inside the shear key; b) occurrence of internal crack in shear key parallel to the shear key; c) damage of concrete at the edge of the shear key; and, d) occurrence of separation along the contact interface. The a)-type failure of the shear key occurs when the diagonal tension force resulting from the combination of tension and shear is larger than the tensile strength of the shear key. The b)-type failure of the shear key happens when the shear force inside the shear key becomes larger than the shear frictional force of the shear key. The c)-type failure of the 
Table 1. Mix proportions of UHPC (in weight ratio).

\begin{tabular}{cccccccc}
\hline Item & W/B & Cement & Silica fume & Sand & Filler & Superplasticizer & Steel fiber \\
\hline Relative ratio & 0.2 & 1 & $0-0.3$ & 1.1 & 0.3 & 0.018 & $2 \%$ (volume ratio) \\
\hline
\end{tabular}

Table 2. Chemical composition and physical properties of binder.

\begin{tabular}{|c|c|c|c|c|c|c|c|c|c|}
\hline \multirow{2}{*}{ Item } & \multirow{2}{*}{$\begin{array}{l}\text { Specific surface } \\
\text { area }\left(\mathrm{m}^{2} / \mathrm{kg}\right)\end{array}$} & \multirow{2}{*}{$\begin{array}{l}\text { Density } \\
\left(\mathrm{kg} / \mathrm{m}^{3}\right)\end{array}$} & \multirow{2}{*}{$\begin{array}{l}\text { L.O.I } \\
(\%)\end{array}$} & \multicolumn{6}{|c|}{ Chemical composition (\%) } \\
\hline & & & & $\mathrm{SiO}_{2}$ & $\mathrm{Al}_{2} \mathrm{O}_{3}$ & $\mathrm{Fe}_{2} \mathrm{O}_{3}$ & $\mathrm{CaO}$ & $\mathrm{MgO}$ & $\mathrm{SO}_{3}$ \\
\hline Cement & 341.3 & 3150 & 1.4 & 21.0 & 6.4 & 3.1 & 61.3 & 3.0 & 2.3 \\
\hline Silica fume & 20,000 & 2100 & 1.50 & 96.0 & 0.3 & 0.1 & 0.4 & 0.1 & - \\
\hline
\end{tabular}

Table 3. Chemical composition of UHPC filler.

\begin{tabular}{|c|c|c|c|c|c|c|}
\hline \multirow{2}{*}{ Item } & \multirow{2}{*}{$\begin{array}{l}\text { L.O.I } \\
(\%)\end{array}$} & \multicolumn{5}{|c|}{ Chemical composition (\%) } \\
\hline & & $\mathrm{SiO}_{2}$ & $\mathrm{Al}_{2} \mathrm{O}_{3}$ & $\mathrm{FeO}_{3}$ & $\mathrm{CaO}$ & $\mathrm{MgO}$ \\
\hline Filler & 0.01 & 99.3 & 0.15 & 0.01 & 0.03 & 0.004 \\
\hline
\end{tabular}

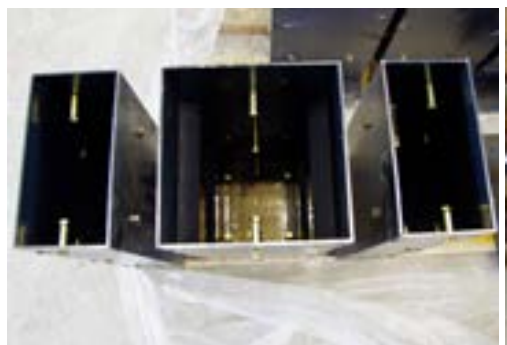

Fabrication of forms

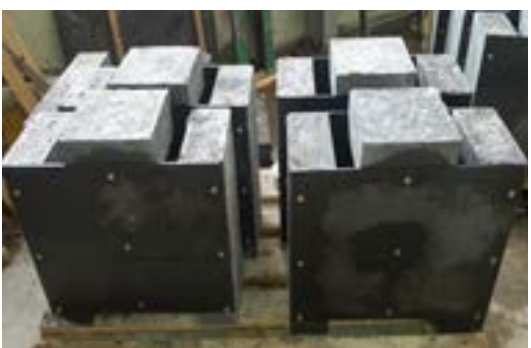

Fabrication of precast segments

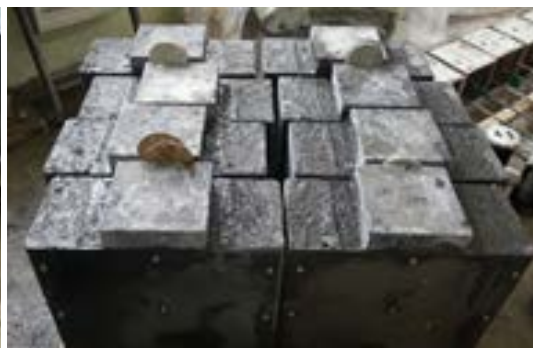

Fabrication of monolithic shear keys

Figure 2. Fabrication of cast-in-place monolithic shear keys.

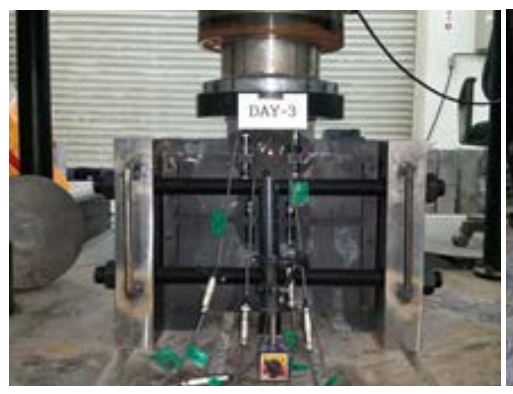

Displacement sensors at the front face

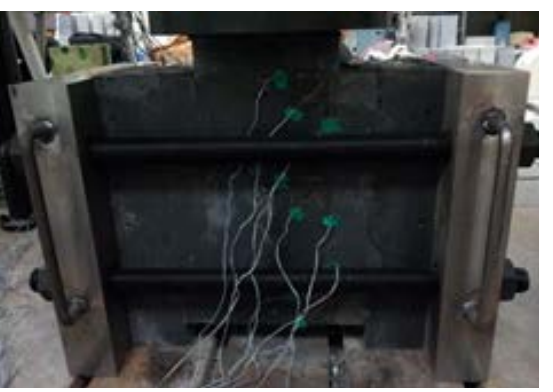

Concrete gages at the rear face

Figure 3. Preparation of shear key test.

shear key appears when the shear key has developed sufficient strength. The d)-type failure of the shear key occurs when sufficient bond force between the shear key and main member is not secured. Figure 4 displays the failure modes of the shear keys observed in this study according to the curing time of the shear keys. It can be seen that inclined cracking developed in the shear keys of all the specimens. Following, the failure of the shear keys in all the specimens was caused by the diagonal tension force (a)-type failure).

The failure of the shear keys observed in this study proceeded as follows. Inclined cracks initiated firstly at the tip of the protruding part of the lower shear key due to the concentration of stress. Thereafter, these inclined cracks propagated according to the increase of the load to result finally in the shear-off failure of the joint when the vertical displacement attained its ultimate state. Failure occurred first in the lower shear key in all the 


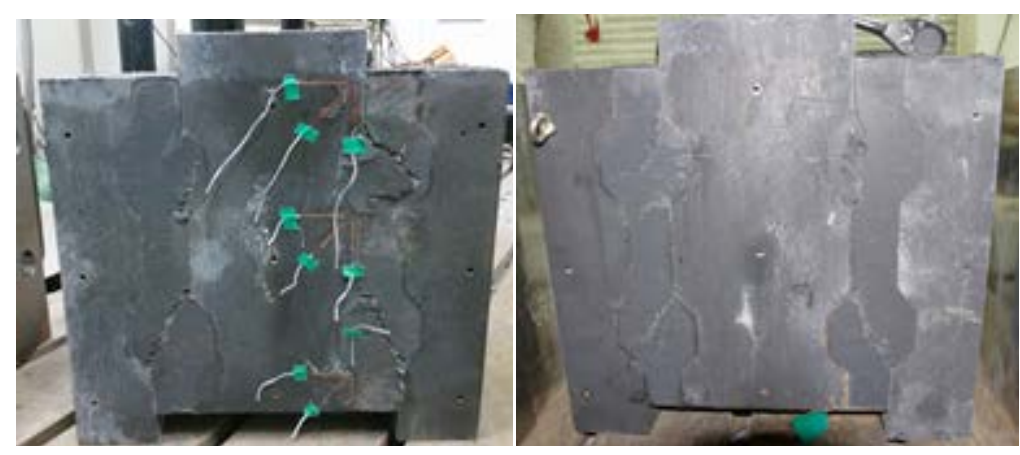

3 days of curing

7 days of curing

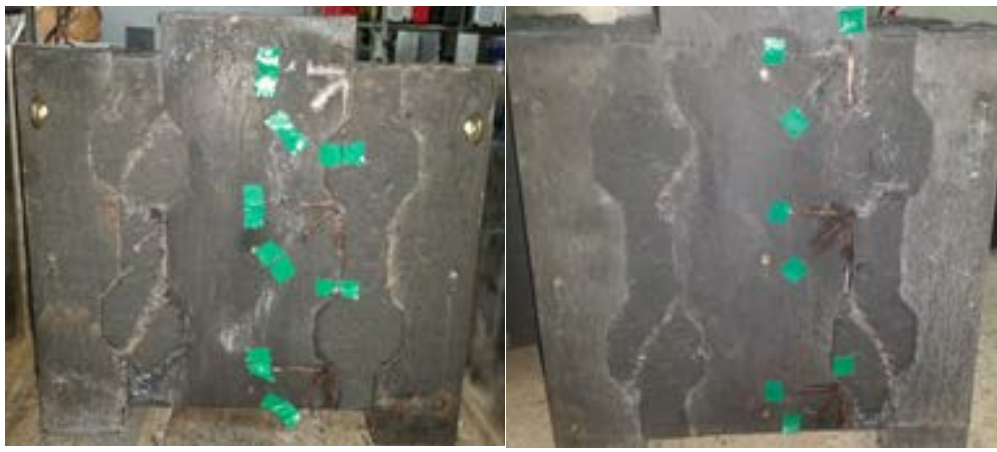

14 days of curing

28 days of curing

Figure 4. Failure mode of shear keys.

specimens because the lower shear key was subjected to tension whereas the upper shear key experienced compression under the application of the vertical load, which means that the vertical load provoked the appearance of a restraint force in the upper shear key. This restraint force acted in the form of compressive stress in the upper shear key and retarded the propagation of the inclined cracks.

\subsection{Strength Characteristics}

Figure 5 presents the results of the regression analysis conducted for the compressive strength ( $\sigma \mathrm{ck})$ and failure load (Pf) with respect to the curing time of the shear keys. The results at 14 days of curing are discarded from the plot due to the dysfunction of the data logger at that time.

It can be seen that the compressive strength and failure load increase with longer curing time of the shear keys. The reason for the increase of the failure load can be found in the higher compressive and tensile strengths of UHPC with respect to the lengthening of the curing time, which improve the resistance to the occurrence of inclined cracks known to cause the failure of the shear key. Furthermore, it can also be observed that the compressive strength and failure load of the shear keys exhibit similar behavior. Accordingly, it can be predicted that the compressive strength as well as the failure load will increase with longer curing time of UHPC. However, the work of Koh et al. [10] revealed that UHPC cured at ambient temperature of $20^{\circ} \mathrm{C}$ develops compressive strength of approximately $60 \%$ at 7 days, $70 \%$ at 28 days and $80 \%$ at 91 days of the compressive strength developed when curing is performed at high temperature of $90^{\circ} \mathrm{C}$ (Figure 6). Accordingly, since it is expected that the compressive strength of the cast-in-place shear keys will show trend similar to that reported by Koh et al. [10], the failure load can be predicted to be smaller than that obtained when the shear keys are fabricated with high temperature curing.

\subsection{Load-Vertical Displacement Relation}

Figure 7 plots the relation between the load and vertical displacement. The results at 14 days of curing are discarded from the plot due to the dysfunction of the data logger at that time.

It can be seen that the shear resistance of the cast-in-place shear key increases with longer curing time. More- 


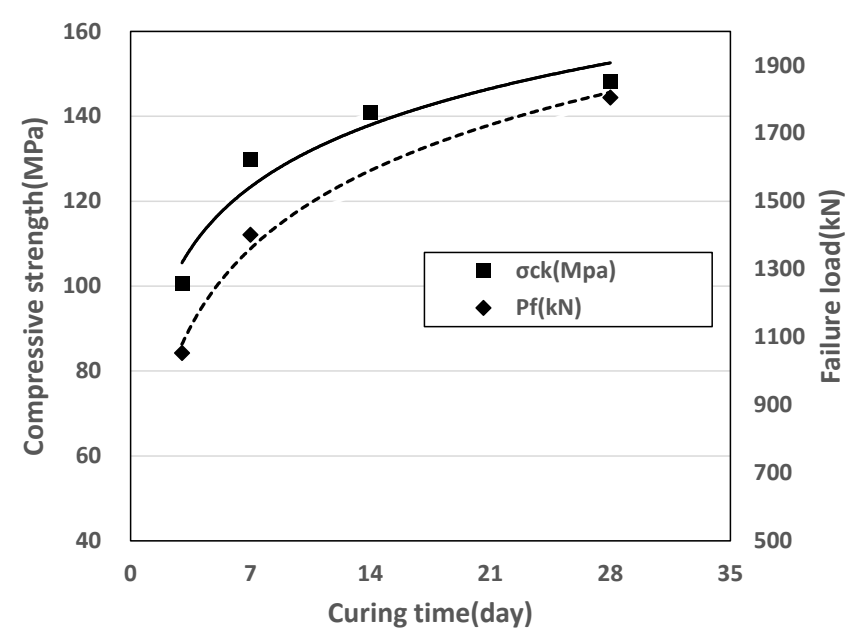

Figure 5. Compressive strength and failure load according to curing time of shear keys.

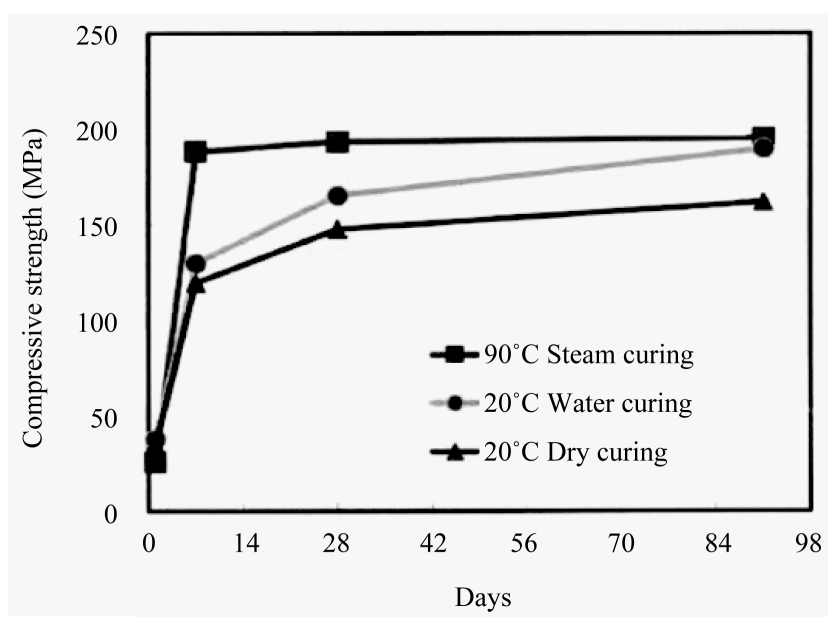

Figure 6. Compressive strength of UHPC according to curing condition [10].

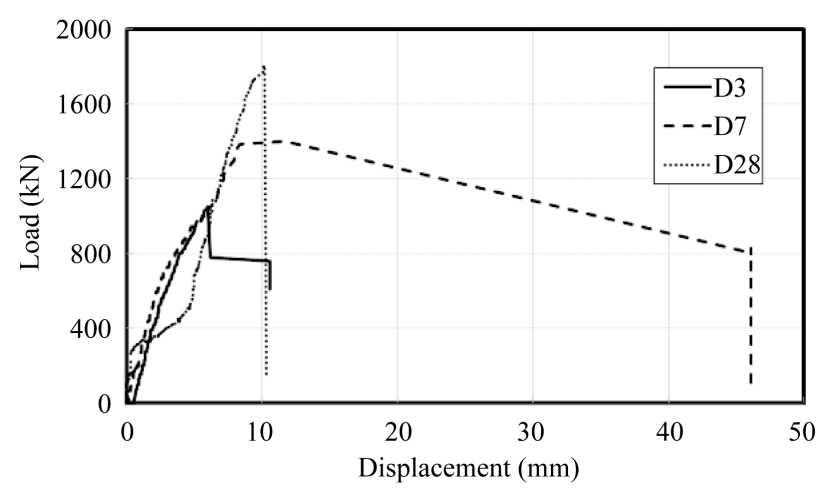

Figure 7. Compressive strength and failure load according to curing time of shear keys.

over, steep enlargement of the vertical displacement of the shear key under constant load can be observed after the failure load for the curing times of 3 days (D3) and 7 days (D7). This can be attributed to the fact that the lower shear key failed first followed by the failure of the upper shear key. In other words, both shear keys re- 
sisted concurrently before the failure load of the upper and lower shear keys, and the upper shear key continued to resist to the applied load after failure of the lower shear key despite of the diminution of the load. However, the shear keys with 28 days of curing (D28) did not experience additional vertical displacement after the failure load due to the simultaneous failure of the upper and lower shear keys.

\section{Conclusions}

This paper presented an experimental study on the behavior of shear keys according to the curing time of concrete in precast segmental joints. The results were used to analyze the cracking and failure behavior of the shear keys and perform comparative analysis of the shear strength characteristics and load-vertical displacement relation. The following conclusions can be drawn:

1) All the cast-in-place shear keys of this study failed through shear failure caused by the diagonal tension force. This failure mode occurs when the diagonal tension force is larger than the tensile strength of the shear key. Consequently, it can be stated that the failure mode of the shear keys will change according to the curing time since the compressive and tensile strengths of the cast-in-place shear keys increase with longer curing time.

2) The compressive strength and failure load exhibited similar increasing trend according to the lengthening of the curing time of the shear keys. However, since the long-term compressive strength of the cast-in-place shear keys cured at ambient temperature is smaller than that developed when cured at high temperature, the failure load can be predicted to be smaller than that obtained when the shear keys are fabricated with high temperature curing.

3) The cast-in-place shear keys appeared to develop higher shear resistance with longer curing time.

These experimental results are believed to provide basic data necessary for the determination of the appropriate assembly time of the segments in structures erected by the precast segmental method.

\section{Acknowledgements}

This research was supported by a grant (13SCIPA02) from Smart Civil Infrastructure Research Program funded by Ministry of Land, Infrastructure and Transport (MOLIT) of Korea government and Korea Agency for Infrastructure Technology Advancement (KAIA).

\section{References}

[1] Sowlat, K. and Rabbat, B.G. (1987) Testing of Segmental Concrete Girders with External Tendons. PCI Journal, 87-106.

[2] Serrette, R.L., Rizkalla, S.H., Attiogbe, E.K. and Heuvel, J.S. (1989) Multiple Shear Key Connections for Precast Shear Wall Panels. PCI Journal, 104-120.

[3] Walter Podolny, J.R. (1982) Recommended Practice for Precast Post-Tensioned Segmental Construction. PCI Journal, 14-61.

[4] Korea Institute of Construction Technology (1992) A Study on Design for Precast Prestressed Concrete Bridges. Final Report, KICT.

[5] Arockiasamy, M., Badve, P., Rao, V. and Reddy, V. (1991) Fatigue Strength of Joints in a Precast Prestressed Concrete Double Tee Bridge. PCI Journal, 36, 84-97. http://dx.doi.org/10.15554/pcij.01011991.84.97

[6] Bishara, A.G. and Papakonstantinou, N.G. (1990) Analysis of Cast-in-Place Concrete Segmental Cantilever Bridges. Journal of Structural Engineering, 116, 1247-1268. http://dx.doi.org/10.1061/(ASCE)0733-9445(1990)116:5(1247)

[7] Koseki, K. and Breen, J.E. (1983) Exploratory Study of Shear Strength of Joints for Precast Segmental Bridges. Research Report, Center for Transportation Research, The University of Texas at Austin, 1-165.

[8] Lee, C.H., Chin, W.J., Choi, E.S. and Kim, Y.J. (2011) An Experimental Study on the Joints in Ultra High Performance Precast Concrete Segmental Bridges. Journal of the Korea Concrete Institute, 23, 235-244. http://dx.doi.org/10.4334/JKCI.2011.23.2.235

[9] Yang, I.H. and Kim, K.C. (2012) Strength of Joint in Floating Structures Constructed with Precast Concrete Modules. Journal of Navigation and Port Research, 36, 197-204. http://dx.doi.org/10.5394/KINPR.2012.36.3.197

[10] Koh, K.T., Park, J.J., Ryu, G.S. and Kang, S.T. (2007) Effect of the Compressive Strength of Ultra-High Strength Steel Fiber Reinforced Cementitious Composites on Curing Method. Journal of the Korea Society of Civil Engineers, 27, 427-432. 